\title{
The effect of rotation on the learning of taste aversions*
}

\author{
LEONARD GREEN and HOWARD RACHLIN \\ State University of New York, Stony Brook, N.Y. 11790
}

Two rats were presented a distinctively flavored liquid while enclosed in an experimental chamber rotating at either 12 or $23 \mathrm{rpm}$. Over the course of the experiment, both rats developed a strong aversion to the liquid. The aversion was shown by failure to drink the liquid when it was offered in a nonrotating experimental chamber and by a reversal of preference for the liquid as compared to water. In this respect, the aversive properties of rotation are similar to the aversive properties of illness-producing agents, such as chemical toxins or X-rays, and are different from the aversive properties of electric shock.

Studies on the effects of rotation have demonstrated marked changes in spontaneous locomotor activity (Eskin \& Riccio, 1966) and in ongoing operant response rate in the rat (Riccio \& Thach, 1968). For example, Riccio \& Thach (1968) found that the rate of barpressing for food reinforcement decreased as a function of increasing rotation speed. They speculated that this decrease might be due to motion sickness brought about by rotation. The usual index of motion sickness in man and monkeys is vomiting and, although the rat is incapable of vomiting (Hatcher, 1924), informal observations indicate other symptoms of illness, such as inactivity, defecation, and failure to eat.

It has also been shown that rats made sick by $\mathrm{X}$-irradiation or ingestion of a toxin, such as lithium chloride, develop aversions for food eaten before or during sickness (Garcia \& Koelling, 1967). If rotation is similar in its aversive properties to these other types of stimulation, it too should be capable of generating aversions to food. The present experiment was performed to test this possibility.

\section{METHOD}

Two individually caged male albino rats with free access to food, approximately 120 days old at the start of the experiment, were deprived of water and reduced to $85 \%$ of their ad lib body weights. The rats were then given 4 days of 15 -min two-bottle initial preference tests using tap water vs $2 \mathrm{~g} /$ liter saccharin solution. With the two bottles daily alternating left-right positions on the front of the home cage, a preference for the saccharin solution was established.

Following the initial preference tests in their home cages, the rats were placed daily for $1 / 2 \mathrm{~h}$ in an experimental chamber, $7 \times 7 \times 9.5$ in. $(17.8 \times 24 \times 17.8 \mathrm{~cm})$, which had a front panel with a single drinking tube containing either water or saccharin solution. The chamber was mounted on a wooden turntable

*Preparation supported by a grant from the National Science Foundation. Reprints may be obtained from the author at the Department of Psychology, State University of New York, Stony Brook, New York 11790. which could be rotated by a variable-speed motor. To minimize centrifugal forces, the chamber was positioned so that while the rat was drinking its head would be over the axis of rotation.

During the first two sessions, only water was available and the chamber remained stationary. During the third session, only saccharin was available, paired with rotation of the chamber. For the first $5 \mathrm{~min}$ of the saccharin session, the chamber remained stationary, after which it was rotated for 25 min. For Rat PN-7, the speed of rotation was $12 \pm 1 \mathrm{rpm}$. For Rat PN-8 the speed of rotation was $23 \pm 1 \mathrm{rpm}$. This pattern of two water sessions followed by one saccharin-rotation session was repeated for 15 days, after which three water-only sessions were scheduled.

On the day following the last experimental session, a 4-day terminal preference test was conducted in the home cages in the same manner as the initial preference tests (15-min two-bottle tests).

\section{RESULTS AND DISCUSSION}

Neither rat drank any of the saccharin solution while the chamber was being rotated. The rats stopped drinking immediately, as soon as rotation started, even on their first exposure to rotation. This contrasts with lithium chloride, X-irradiation, and other illness-producing agents which usually begin to suppress drinking several minutes after application. Table 1 shows the amount of liquid consumed during the first $5 \mathrm{~min}$ (before rotation began) on each saccharin solution day and on the preceding water day. The rat rotated at $23 \mathrm{rpm}$ had virtually stopped drinking during the $5 \mathrm{~min}$ prior to the rotation by the third saccharin-rotation session. The rat rotated at $12 \mathrm{rpm}$ had markedly reduced its intake of saccharin by the fourth session and stopped totally by the fifth. No consistent change in drinking was evident on water days. The last session (after 2 water-only days) was again run with the water solution. The last row of Table 1 (labeled $\mathrm{W}$ ) demonstrates that the aversion was specific to the saccharin flavor and was not due to temporal discrimination (every third day) or satiation.

\section{Table 1}

Amount of Liquid Consumed (in Milliliters) for Each Saccharin Day and its Preceding Water Day During the First 5 Min

\begin{tabular}{|c|c|c|c|c|}
\hline \multirow{2}{*}{$\begin{array}{c}\text { Test } \\
\text { Sessions }\end{array}$} & \multicolumn{2}{|c|}{$\begin{array}{c}\text { PN-7 } \\
12 \mathrm{rpm} \\
\end{array}$} & \multicolumn{2}{|c|}{$\begin{array}{c}\text { PN-8 } \\
23 \mathrm{rpm} \\
\end{array}$} \\
\hline & Water & Saccharin & Water & Saccharin \\
\hline 1 & 8.0 & 9.5 & 11.0 & 10.5 \\
\hline 2 & 8.0 & 9.0 & 11.0 & 8.0 \\
\hline 3 & 10.0 & 6.5 & 11.5 & 0.5 \\
\hline 4 & 10.0 & 2.0 & 12.0 & 0.5 \\
\hline 5 & 10.0 & 0.0 & 10.5 & 0.0 \\
\hline $\mathrm{W}^{*}$ & 10.5 & 11.5 & 11.0 & 11.0 \\
\hline
\end{tabular}

${ }^{*}$ Represents the final 2 water-only days 
Table 2

Mean Relative Amount of Saccharin Consumed on the Initial and Terminal Preference Tests

\begin{tabular}{|c|c|c|c|}
\hline & \multirow[b]{2}{*}{$\begin{array}{c}\text { Rotation } \\
\text { Speed } \\
\text { (rpm) }\end{array}$} & \multicolumn{2}{|c|}{$\begin{array}{l}\text { Relative Percent } \\
\text { Saccharin }\end{array}$} \\
\hline & & $\begin{array}{c}\text { Initial } \\
\text { Preference } \\
\text { Tests }\end{array}$ & $\begin{array}{c}\text { Terminal } \\
\text { Preference } \\
\text { Tests } \\
\end{array}$ \\
\hline $\begin{array}{l}\text { PN-7 } \\
\text { PN-8 }\end{array}$ & $\begin{array}{l}12 \\
23\end{array}$ & $\begin{array}{l}64.20 \% \\
75.35 \%\end{array}$ & $\begin{array}{l}4.60 \% \\
4.75 \%\end{array}$ \\
\hline
\end{tabular}

Table 2 shows the mean relative intake of saccharin solution during the 4 days of initial and terminal preference tests. This measure was obtained by dividing the amount of saccharin consumed by the total amount of saccharin plus water consumed during each of the preference days. Both rats preferred saccharin on the initial tests, and both reversed their preference strongly toward water on the terminal tests.

The present results demonstrate that rats learn to avoid a specific flavor when it is paired with rotation, just as they do when the flavor is paired with lithium chloride or X-irradiation (Garcia \& Koelling, 1967), but which they fail to do when the flavor is paired with continuous or discrete electric shock (Green, Bouzas, \& Rachlin, 1972).

Rotation, as an aversive stimulus, despite its external application and relative immediacy, seems more similar to illness-producing stimuli, such as lithium chloride, than to pain-producing stimuli, such as electric shock. Other studies will direct themselves at further elucidating the similarities and differences among these aversive stimuli.

\section{REFERENCES}

Eskin, A., \& Riccio, D. C. The effects of vestibular stimulation on spontaneous activity in the rat. Psychological Record, $1966,16,523-529$.

Garcia, J., \& Koelling, R. A. A comparison of aversions induced by $X$-rays, toxins, and drugs in the rat. Radiation Research, $1967,7,439-450$.

Green, L., Bouzas, A., \& Rachlin, H. Test of an electric-shock analog to illness-induced aversion. Behavioral Biology, 1972, 7, 513-518.

Hatcher, R. A. The mechanism of vomiting. Physiological Review, 1924, 4, 479-504.

Riccio, D. C \& Thach, J. S. Jr. Response suppression produced by vestibular stimulation in the rat. Journal of the Experimental Analysis of Behavior, 1968, 11, 479-488.

(Received for publication November 6, 1972.) 